\title{
EDUCATIONAL WRITINGS
}

\section{SUMMARY OF THE LITERATURE IN SCIENTIFIC METHOD IN THE FIELD OF CURRICULUM- MAKING}

\author{
J. F. BOBBITT \\ School of Education, University of Chicago
}

An attempt is being made at the present time to develop a technique of scientific method appropriate to the different types of work that are to be carried on in a well-developed school system. For a great many years our educational laboratories have been scientifically testing out the educational efficacy of different methods of teaching. Our Bureaus of Educational Measurement have been finding ways of determining in a scientific manner the nature and the significance of the results that are being obtained in the classroom. Scientific methods are likewise being applied to cost-accounting, budget-making, child-accounting, grading and promotion, etc.

In educational work, however, a primordial thing is the curriculum. This really must be the starting-point of everything that goes on within the system. If the curriculum has not been scientifically determined then there is a large degree of fatuity in attempting to apply scientific methods to the processes involved in carrying on the prescribed work.

The curriculum, however, relates to the ultimate purposes of education and our profession is not thus far agreed as to these ultimate purposes. But of one thing we are certain. The curriculum must relate to the current needs of men and women in the multifarious affairs of an active world. It must be designed to fit the growing generation for an effective performance of the activities involved in these affairs. The curriculum cannot, therefore, be discovered within the classroom, nor from anything that goes on within the school system. It must be discovered in the needs of men and women in their endlessly complicated world of active affairs. School men must go out of the schoolroom, in fact outside of the school system, to discover the elements that are to be included in the courses of training. Scientific method applied to the curriculum cannot therefore be a simple matter of the scientific laboratory, of classroom research, of schoolroom records and measurements, etc. It must be a technique of determining the needs of men within the various fields of their activities.

In the development of the necessary technique of scientific curriculummaking our profession has been making rather rapid strides during the past 
five years. We are discarding our older crude methods of generating a curriculum out of personal opinions, out of some narrow, special, educational philosophy, or merely borrowing courses of study made by others and handed on through the channels of tradition and indolent imitation. We are learning that curriculums are not to be made; they are to be discovered.

In enumerating some of the articles and books that reveal this rapidly developing movement, for the sake of some completeness, we shall refer to certain writings that have for some time been well known to the leaders of the profession. They seem not yet, however, to be altogether appreciated in their bearing upon the general problem of scientific method in the field of curriculummaking. In referring to these better-known studies our purpose is to point out their relationship to the more general problem.

Of the old-line subjects it is spelling that has up to the present time received the greatest amount of attention. This is probably because of the relative simplicity of the problems. Quite a number of studies have been made by way of discovering those common English words that actually or probably enter into the written vocabulary of people in general. One of the first of these studies appeared in a pamphlet entitled Six Thousand Common English Words, by Mr. R. C. Eldridge (I9II). Mr. Eldridge made an analysis of the vocabularies of 250 different articles found in four issues of four Sunday newspapers published in Buffalo. He discovered a total vocabulary of 6,002 different words. These he set forth as a proper spelling-list, since, as he assumes, the vocabulary of everyday life and that of the newspaper are in all probability practically identical. This unproved assumption is a weak point in his method. He has tabulated the words which reporters and editorial writers must be able to spell. He has not actually tabulated the words which men and women in general are called upon to spell in the written work which they themselves produce. For most individuals this is not large in amount. It is extremely probable that the number of words which they need to spell for this writing is very considerably less than the number to be found in their reading vocabulary, which may well approximate that of the usual newspaper. Mr. Eldridge secured objective evidence as the basis of his word-list; but he went to the wrong place to secure his evidence.

A second well-known study is Mr. Ayres's Spelling Vocabularies of Personal and Business Letters. ${ }^{\mathrm{x}}$ He tabulated the words written by 2,000 different individuals in 2,000 short letters and found a total number of 2,00I different words. He went to the activities of men and women in the world of affairs and discovered their needs within those situations where spelling actually functioned. It may be objected that he chose too restricted a field of functioning for his purpose; that men and women are called upon to spell in the writing of more things than personal and business letters; that business letters tend to be

I Spelling Vocabularies of Personal and Business Letters. By L. P. Ayres. New York: Russell Sage Foundation, rgr3. 
rather stereotyped and to employ but a meager vocabulary; that in tabulating only the first word of every line in the letter many words escaped that would have found a place had all words been tabulated; and that, therefore, the list is too incomplete for a spelling curriculum. Even should there be some degree of validity in these various objections, his study exhibits the application of objective, impersonal, scientific methods to the problem of discovering the list of words that actually function in the aduIt world.

The same type of study was carried out by W. A. Cook and M. V. O'Shea and the results published in a book entitled The Child and His Spelling. ${ }^{\mathrm{r}}$ They tabulated the vocabulary employed in the family correspondence of thirteen adults involving a total of some 200,000 words. They discovered a list of 5,200 different words. While the general outline of their method is sound, it must be again noted that they also have studied the spelling function in too restricted a portion of the adult world. Scientific method demands that we secure an adequate sampling of the writing of all kinds on the part of all social classes, by way of formulating the curriculum of spelling instruction that is to be given equally to all.

The most elaborate scientific study of the vocabulary of spelling was made by Professor W. Franklin Jones and published in his Concrete Investigation of the Material of English Spelling. ${ }^{2} \mathrm{He}$ and his collaborators encouraged $\mathrm{I}_{50}$ children in each of the grades from the second through the eighth, or 1,050 children in all, to write letters, compositions, reports, etc., on all sorts of subjects until each student had used in his writing practically his whole writing vocabulary. About 75,000 papers were gone over and approximately i 5,,00,$\infty$ words tabulated. After omitting words used only one or two times in a grade, he discovered 4,532 different words, distributed as follows:

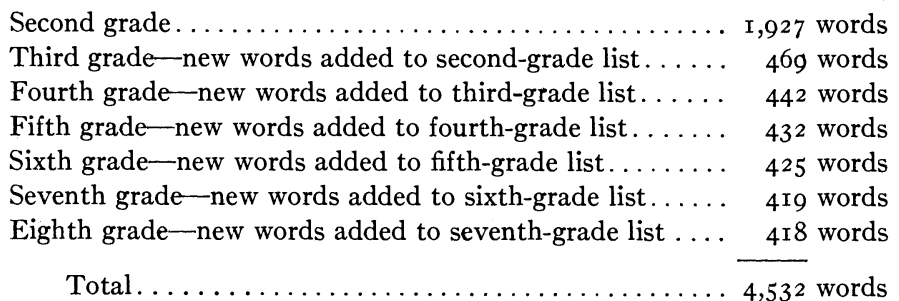

Since this study was published Professor Jones has been working upon the writing vocabulary of high-school and college students with the expectation that he can present a functioning list of words appropriate for each of the stages of development.

'The Child and His Spelling. By W. A. Cook and M. V. O'Shea. Indianapolis: Bobbs-Merrill Co., rgr4.

${ }^{2}$ Concrete Investigation of the Material of English Spelling. By W. Franklin Jones. University of South Dakota, Vermilion, S.D., I9I4. \$o. Io. 
We are here mainly concerned with the validity of his method. It must be kept in mind that school life and the writing that goes on during this period do not exist for themselves, but as preparation for the activities of adult life. It may be assumed that the vocabulary needed for the preparatory activities of school life must necessarily be about the same as that needed for those activities of adult life for which the schools prepare. Doubtless this assumption would be valid if all school activities were closely knit up with the community life, a condition which does not exist in any adequate degree as yet. School life at the present time exists pretty largely in isolation from community life. To analyze, therefore, the things that go on within the classroom by way of finding the things needed by adults in the world of practical affairs is a very insecure method of focusing the curriculum so as adequately to meet community needs. Professor Jones's heroic study is probably the most valuable single one yet made in the field of spelling. Yet it must be confessed that it cannot represent the final word since he has not applied his scientific methods to the wide and varied field of adult functioning.

A more recent study is that of Professor Hugh Pryor entitled "A Suggested Minimal Spelling List." ${ }^{\prime}$ He takes the lists of Jones, Ayres, Eldridge, Cook and O'Shea, the lists used in making Ayres's measuring scale, the arbitrary lists of certain specially devised spelling books by Hicks, Chancellor, Studley and Ware, and two or three other lists more or less arbitrarily prepared, from which he has compiled a composite list. He presents this composite list as a suggestive minimal spelling list.

The validity of his method must be largely measured by the validity of the method employed in drawing up each of the many individual lists of words from which his own is made. Some of these represent nothing more than the arbitrary judgment of individuals or committees. One is a newspaper vocabulary. One of those concerned indirectly, through Ayres's spelling scale, is a list of the 350 words most commonly used in the English Bible and certain English classics. Two or three of the lists are like those of Professor Jones and represent children's vocabularies as exhibited in their compositions. If all of the twelve or fifteen studies he used had been of the type of Ayres's and Cook and O'Shea's, each of them presenting some partial aspect of spelling functioning in the adult world, then the list that he presents would doubtless be better than any one of the partial lists. Using, however, several compilations that are not scientifically valid it is probable that the composite list is not as good as certain individual lists. Certainly his method is not as good.

As a matter of fact, the application of scientific method to the problem of drawing up a curriculum in spelling involves so complicated a task that it cannot be adequately carried out by any single man, or even any single educational group. The time has come, however, when our profession should

${ }^{1}$ Sixteenth Yearbook of the National Society for the Study of Education, Part I (I9I 7), pp. 73-84. Public School Publishing Co., Bloomington, Ill. 
consciously make decision as to what constitutes scientific procedure in the solution of the problem, and should then proceed with the large co-operative professional task of accomplishing the work. Enough has been done, in the pioneer studies referred to, to point the way.

Another field in which the professional leaders are attempting to work out a scientific method of discovering the curriculum is that of grammar. In this field it appears that Professor W. W. Charters has done one of the most important pieces of pioneer work as recorded in his A Course of Study in Grammar Based upon the Grammatical Errors of School Children of Kansas City, Mo. ${ }^{\mathrm{x}} \mathrm{He}$ proceeds upon the assumption that the purpose of grammar is the elimination of errors in the oral and written speech. He assumes that an individual masters his mother-tongue mainly from unconscious imitation as he hears and uses language in association with his fellows. Here and there, however, either he fails to imitate sufficiently for entire correctness or there is a certain degree of imperfection in the language of his associates which he unconsciously imitates. In either case here and there he makes mistakes. Now there is no need of giving him information concerning grammatical relationships of his speech in so far as he makes no mistakes. It is needed only where the mistakes are made.

Starting with these assumptions one would suppose that the study would aim at securing a list of the grammatical mistakes that are made by the adult world, and especially that portion of it which has not secured adequate grammatical discipline; we should thus seek to discover just what aspects of grammar need to be made to function better in adult speech. Instead, however, of analyzing the speech of mature men and women, the study set out to discover the errors made in the oral and written speech of intermediate and grammar-grade pupils in the public schools. The teachers were asked to carry a notebook constantly for five days and jot down every grammatical error made orally by any pupil in their presence. They were asked also to examine all written work handed in during a period of three weeks by way of discovering all of the errors made by the children in their writing. It was discovered that the children made twenty-one types of errors in their oral speech and twentyseven types in their written work. Thus far the study proceeds on the basis of objective evidence. At this point it is handed over to the personal judgment of the investigator. On the basis of the twenty-one or twenty-seven types of errors he presents the grammatical rules which in his judgment, if followed, will serve to prevent the occurrence of those errors. He also presents the additional grammatical information which in his judgment appears to be necessary for a proper understanding of these twenty-one or twenty-seven grammatical rules. This body of grammatical information then makes up the minimal essentials of a course of study in grammar.

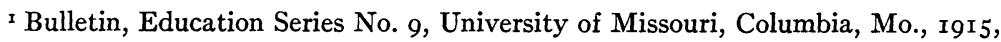
pp. 45. Out of print. 
Since this study appeared similar studies have been made upon the errors of school children in northern Illinois, Boise, Cincinnati, Speyer School, Bonham, Tex., Columbia, Mo., and Detroit. A composite report of these studies is presented by Professor W. W. Charters in an article entitled "Minimal Essentials in Elementary Language and Grammar." In all of these studies the same types of grammatical errors are discovered. They do not always agree as to the relative frequency of the different types of errors, but since the purpose of the grammatical teaching is the elimination of all kinds of errors that occur with an appreciable degree of frequency, minor discrepancy is of no practical consequence.

It will be observed that the method employed in these studies in the grammar field is very different from that employed in the spelling field, in the latter of the studies referred to. In the spelling studies the attempt was made to discover the entire list of words that function in the writing of the children. The purpose is to devise a program of direct training that involves in a positive way all the things that function in one's normal spelling activities. The grammar study in quite the reverse way makes no attempt whatever to discover all of the grammatical relationships involved in the language of the children. It does not aim to give direct conscious training in all the forms of functioning. It expects to leave most of the training to indirect unconscious learning and to make conscious only that minimum quantity of functioning where the pupil or adult must be watchful against error. This also is a positive program, but it is a very different type of program and springs from a more mature and complete type of educational philosophy. Professor Jones recognizes the validity of this plan of work as shown by his elaborate study of the spelling errors found in the compositions. It is not improbable that a study of the errors made in spelling will be of more practical value for curriculummaking in spelling than a study of the entire writing vocabulary.

Owing to the definiteness and relative simplicity of the field of elementaryand high-school mathematics, one might reasonably expect to find here some good examples of the application of the method of objective analysis of adult needs as the basis of courses of study. As a matter of fact, however, one finds very little work of this character. Practically everywhere courses of study in arithmetic and high-school mathematics are made up on the basis of guess, personal opinion, or a combination of the two. No attempt has been made to secure objective evidence as to the nature of the mathematics that actually functions in the affairs of the adult world. The reports of the International Commission on the Teaching of Mathematics entitled Mathematics in the Elementary Schools of the United States and Mathematics in the Public Secondary Schools of the United States merely present summaries of current practices. They make no contribution whatever to the solution of the problem of scien-

' Sixteenth Yearbook of the National Society for the Study of Education, Part I (I9I7), pp. 86-I ro. 
tific curriculum-making in this field. They give little evidence of being aware of the need of the development of such technique prior to the formulation of courses of study.

One of the notable contributions was that by President W. A. Jessup entitled "Current Practices and Standards in Arithmetic." judgment of almost one thousand school superintendents as to the arithmetic topics that should be eliminated, those that should receive a diminished emphasis, and those that should receive an increased emphasis. Such study is based upon the presumption that superintendents are well informed as to the mathematical processes that are and need to be carried on by the adult population of the different communities. There are reasons to think that this assumption is not as well founded as we should wish. Superintendents have general impressions in the matter, rarely do they have accurate information.

The modes of procedure and the results of somewhat different types of work are presented in an article by Professor G. M. Wilson entitled "A Survey of the Social and Business Use of Arithmetic."' The article presents two types of study, each of which is suggestive as to methods of curriculum-making. The first study described was made when he was superintendent of schools in Connersville, Ind. He sent out a letter to the business men of the community in which he presented to them a list of arithmetical topics with the request that they mark those that should be eliminated, those that should receive diminished emphasis, those that should receive increased emphasis, and those not hitherto taught that should be taught. The business men were to mark the topics on the basis of their practical experience. As a result they voted to eliminate such topics as troy weight, apothecaries weight, longitude and time, surveyors' table, greatest common divisor, and a dozen others. They voted to incorporate such topics as saving and loaning money, mortgages, modern banking methods, building and loan associations, investing money, and quite a number of others. This plan attempts to discover the actual mathematical functioning. But the judgment of these men, naturally, was very considerably distorted by their traditional ideas obtained during school days as to what should be included in the arithmetic. It is a long step in the direction of good scientific method, since it is a step in the direction of a determination of the actual reality to be found in the adult world. It must be admitted, however, that the opinions of business men do not always constitute reliable scientific evidence.

The other study made by Mr. Wilson presents a much nearer approach to good method. He conceived a plan of having adult men and women make note of the mathematical operations which they themselves performed during

${ }^{2}$ Fourteenth Yearbook of the National Society for the Study of Education, Part I (I9r5), pp. Ir6-30.

${ }^{2}$ Sixteenth Yearbook of the National Society for the Study of Education, Part I (I9I 7), pp. $128-42$. 
a period of two weeks. By having the pupils of the sixth, seventh, and eighth grades collect the problems from their parents, he found it possible to secure reports from I,457 different individuals in eighteen school systems, city and rural. The individuals belonged to about one hundred different occupations. They contributed some 5,036 different problems. It was possible from these actual problems solved to discover the kinds of addition, multiplication, subtraction, division, common fractions, decimal fractions, interest, and other problems that individuals are actually solving in their current affairs. He discovered the topics to which practical application of the arithmetic was actually made. It is not a final piece of work, since it is too slight, refers to too restricted a group, and is for too short an interval of time. In general outline, however, it presents the most highly developed type of scientific technique yet presented to the profession for curriculum investigation in the mathematical field. To carry it out, he leaves the classroom, the traditional textbook, and all the mathematical traditions behind him. He goes out into the actual world of affairs to discover the mathematics that people are actually using. He suggests that the forms of functioning discovered are the things in which they need to be trained. He was making only a study of the arithmetic. The plan is one that can be applied equally well to a discovery of the algebra, the geometry, and the other mathematics needed by the world in general, or by any specific class.

From this illustration, especially, it may appear that scientific curriculummaking aims at a narrow utilitarianism. This, however, is not and cannot be the case. It cannot be scientific except as it looks to all forms of functioning within the world of human affairs. So far as mathematics functions indirectly this type of functioning must be discovered as completely as that which is direct. So far as mathematics is found to be a desirable leisure occupation, or a functioning disciplinary occupation, it needs to be considered no less than when it appears in connection with one's vocational labors.

In developing courses of training in the field of vocational education our profession has been relatively untrammeled by tradition and has been therefore free to develop and employ good scientific methods in drawing up the courses. One of the best examples is to be found in the recent Report of the Indianapolis, Ind., Survey for Vocational Education. ${ }^{\mathrm{I}} \quad$ It began by analyzing the community into the various occupational groups of which it is made up. Special investigators were then delegated to make a careful study of the situation as regards each of these important vocational classes. The report presents a large number of tables which show for each vocational class the various operations which members must perform and for which they must through training receive the requisite knowledge and skill. A second column enumerates the "Knowledge about Jobs and Materials." A third makes a list of the tools and the materials

${ }^{1}$ Charles H. Winslow, State Board of Education, Bulletin No. 2I, Indianapolis, 1917. 2 vols. Pp. 400, 527. A limited number for distribution. 
which they must understand. A fourth column presents a list of the general knowledge of technical processes which each worker must possess in order to do his work efficiently. A fifth presents a general outline of the mathematics which they must know rightly to understand the various operations and to perform their labors. A sixth column presents in general outline the science which they need, and a seventh the elements of drawing and design. It is possible that these tables are very incomplete; that they do not list very many things which need to be included in the training of these various vocational workers. There seems, for example, to be omission of certain necessary social, economic, sanitary, and civic studies that relate intimately to the vocations. In general outline, however, and in intention the method appears to be scientifically sound. It seeks primarily to secure objective evidence as to those adult activities for which the schools must train. It includes nothing but that for which an affirmative case can be made out previous to its inclusion in the curriculum. It has nothing to do with mere opinions, with educational tradition, with special and partial educational philosophies. Its conclusions can be verified by other investigators working entirely independently. It must be admitted that this is a pioneer piece of work and perfection is not to be expected in this stage of the development of scientific methods. It lays the foundation for further improvement. Since this report probably represents the high-water mark of good method in this field, there is no need here to refer to those previous reports of work in other cities which represent earlier stages in the development of the method.

Attempts are being made to make application of objective methods in the formulation of courses of training in the field of the social studies. An interesting example is that reported by Professor W. C. Bagley in his article "The Determination of Minimum Essentials in Elementary Geography and History." The first study reported in this article, on geography, starts out with the assumption that geography functions largely in one's reading of newspapers and magazines which deal with the social world of current affairs. Rightly to appreciate the news of the day, one must understand the geographical setting of the various events. It is not necessary to understand those portions of the earth where nothing is going on; where little is going on little geographical information is needed; where much is going on more information is needed and it is more essential that it be well in hand. Through his graduate students, Dr. Bagley therefore made a study of the geographical references found in the large number of newspapers and magazines distributed over a series of years. They tabulated the frequency of reference to different countries, different cities, rivers, oceans, seas, straits, etc. They tabulated references to place geography, political geography, industry, commerce, products, races, customs, religions, education, etc.

I Fourteenth Yearbook of the National Society for the Study of Education, Part I, pp. $13 \mathrm{x}-46$. 
The historical references in the same article were also tabulated as a means of discovering the type of historical information that was actually functioning in the reading life of the population. He made the discovery in this wise of the names of the historical personages most often alluded to, of the historical topics and events, historical periods, etc., most often employed in current newspaper discussion.

Professor Bagley claimed no finality for his results, nor even for the validity of the method. It is presented as a suggestion of method. It can be seen, however, that it goes outside of the textbooks, and the classrooms, and the school environment in general, and attempts to make discovery within the world of adult affairs itself of the modes of functioning of geography and history. It seeks objective evidence. These are marks of good scientific method. It is probable that it looks too much to merely the direct modes of functioning and insufficiently to a far more important indirect functioning, which does not appear on the surface. It further is clearly the analysis of too restricted a field of human activity. Men do many things besides read newspapers for which historical and geographical experience is needed as a background. This is, however, merely to say that the study is a pioneer one and attacked only a small portion of the field. As an illustration of method, however, the suggestion appears to be excellent.

In the same article Professor Bagley reports a curriculum questionnaire study on history. He asked 150 members of the American Historical Association to select the twenty most important dates from a list of fifty-two which he submitted, and to rank them in the order of their importance. As an outcome of the study, he presents what purports to be the twenty most significant historical dates. These, however, represent only the consensus of opinion of specialists in a particular field who as a matter of fact make no great pretense to an understanding of the social thought or needs of the present generation. They do not really know any more than the laymen what actual history is functioning in the minds of the present generation. This study failed to get outside of the academic atmosphere. It attempts to discover the curriculum within the confines of the fields of education in general. It is not there to be discovered. The plan appears to present little suggestion for scientific method.

The feeling is rather widespread that it is possible to make discovery concerning, or at least to throw important light upon, the proper content of the curriculum by an analysis of the textbooks employed in the field of a given subject. One of the most carefully wrought examples of this type of study is one for which Dr. Bagley is responsible, entitled The Content of American History as Taught in the Seventh and Eighth Grades. ${ }^{x}$ The study presents an elaborate and accurate analysis of the topical content of twenty-three American history texts published in the past fifty years, representing four rather distinct, successive periods of publication. An attempt was made to discover the trend

${ }^{5}$ Bulletin No. 16, University of Illinois, School of Education Studies, I9r6, Urbana, Illinois. 
of development during these fifty years, as regards references and bibliographies, questions, outlines, problems, style of treatment, the use of anecdotal material, pictures, maps, etc. The percentage of space given to each of the many historical topics treated in the various histories is then presented in a series of detailed tables. In connection with the tables representing the major historical stages in our national history is presented a list of the names of the great personages who figured most prominently in the history of each period. In amount of labor involved, the study is of heroic size. Its accuracy is unquestionable. It presents an interesting body of facts as to what has been going on within the curriculum of elementary United States history. It does not, however, present any suggestions for scientific method in curriculum-making. The study employs a rigorous type of scientific method in the organization of its data. It is handling data, however, from a source that throws no light whatever upon the historical needs of the population. As a piece of historical research the study is valuable.

A study of an analogous type is the determination of the consensus of practice from a tabulation of the data found in a large number of published courses of study. An example of this type is one for which the present writer is responsible, entitled "Library and Supplementary Reading Books Recommended for Use in Elementary Schools." ' The printed courses of fifty important American cities were examined and all supplementary reading recommendations tabulated by grades. The article, therefore, presents a list of the books most commonly used in the first grade in the order of their frequency, the list for the second grade, etc., through all of the eight grades. This purports to be an attempt to discover what ought to be from what actually is going on within the field. It presents a consensus of judgment. The study doubtless has certain values in pointing to the grade in which any given book might be placed after it has been chosen for the curriculum. The study, however, presents no basis on which to make the original choice of the books. It is, again, an attempt to discover within the classroom what ought to be going on within the classroom, when as a matter of fact the reading experience which should be prescribed for the development of children is not to be determined from an examination of that experience itself, but from an analysis of the world of affairs in which that reading experience is expected to bear fruit.

Attention is called to these two unfruitful types of curriculum study because of the frequency with which these methods are actually employed. They make good research problems; they have a value; but it must be kept in mind that the results reveal the nature of the past, not the needs of the present or of the future. They are historical studies, not forward-looking, practical, curriculum-discovery studies.

${ }^{1}$ O. F. Munson and J. H. Hoskinson, Sixteenth Yearbook of the National Society for the Study of Education, Part I (I917), pp. 33-57. 


\section{COMMENT ON CURRENT EDUCATIONAL WRITINGS}

I. A new summary of standard tests. - The measuring movement in education has developed a voluminous literature. Recently school men have felt the need for a systematic organization of the tests and scales which have come from the activity of the measurers. During the last year several rather complete annotated bibliographies have been published and two textbooks have come out. The editor has criticized the latter on the following counts: (I) they have not selected the best representative scales and standard tests to put before teachers; (2) they have included almost no evaluation of the tests; (3) they have not shown how they can be used to improve teaching in a definite way; and (4) they have not supplied school people with complete bibliographies of the tests and scales that are available.

Educational tests and measurements by Monroe, De Voss, and Kelly ${ }^{\mathrm{r}}$ we recognize to be an improvement on the previous two textbooks. It is a brief textbook which aims to place in the hands of school teachers and administrative officers a summary of the tests and scales which have been published to the present time in each of the elementary- and high-school subjects of study. A brief chapter is given on the inaccuracy of present school marks, to introduce the need for quantitative measurement in school practice. Following this the tests are presented in the next six chapters by subjects-arithmetic, reading, spelling, handwriting, language, and the high-school subjects. The material is organized in each chapter under a fourfold scheme: (r) a brief discussion of the problem of testing abilities in the subject of study in question. This, on the whole, is very brief and hardly an adequate analytical treatment of that problem. (2) The presentation of each of the standardized tests and scales which has appeared for the measurement of abilities in that subject. It should be pointed out that no detailed principles are laid down for the critical evaluation of the scales in question. Neither do the authors make such critical evaluation, the presentation aiming to be thoroughly informational. This aim is carried out to the extent that a non-technical presentation is given of each of the tests. The authors do not reprint the scales and tests in full, but select typical portions to illustrate what has been done, referring the reader to the printed test or scale, which he can secure if he desires. (3) Standard scores which have been set up as a result of the use of the tests and scales in each subject. This portion of the work places in the hands of the reader in condensed form a fairly good summary of the published standards. (4) A section is included in each chapter which discusses how to use the results of measurement. This cannot be said to be an intensive psychological discussion but goes so far as to point out established "laws" of habit formation, memory, etc., with an elementary treatment of the application of these laws to instruction. The authors, however, make very little psychological analysis of the

s W. S. Monroe, J. C. De Voss, and F. J. Kelly. Boston: Houghton Mifflin Co., 1917. Pp. xxii+309. \$1.50. 
learning process in each of the different subjects. The book provides the reader with very complete bibliographies and on the whole will fill a need which has been experienced by school men recently for a fairly complete compilation of the tests which are now available.

2. An experimentally determined course of study in elementary-school English.-The movement for economy of time has nowhere been as well carried out in actual school practice as in Mr. Mahoney's Standards in English. ${ }^{\mathrm{I}}$ It presents an experimental course of study which is the result of two years of investigational work carried on by the author while assistant superintendent of schools in Cambridge, Mass. It makes use of scientific method in that the actual status of results of elementary instruction in English was first determined by testing. Measurement of attainments revealed a condition which was admittedly unsatisfactory. Careful determination by the judgment of teachers as to what was the matter with the English course resulted in the establishment of minimum standards for graduation from the elementary school. Mr. Mahoney's succinct statement of this minimum standard and of the fundamental problem recognized by the whole investigation is well worth quoting:

These points-minimum standards - were made the end to be attained by the new course of study which it became necessary to write. From the standpoint of economy of time, the first advance step had been taken by defining clearly just what was most conspicuously the matter with the work in English at a certain stage. To remedy what was wrong, teachers were told very distinctly what to do. They might do more. They might teach the idea of the paragraph. They might teach various points of technique and of style in the upper grades. In the course of study as laid out, work of this kind was included. But there was to be no more "shooting in the air." Certain things were to be done, regardless. And these things were of so elementary a character that the teachers knew they could be done.

The next step was to set down in a course of study how they could be done with most economy of time, so that further time might be secured for points only less essential.

We wish that we had the space to quote more liberally from this publication. We shall be able to present but a sketch of what the author has done. In brief, he has published a course of study which has been tried out and proven to be very successful in correcting the defects noted above. Part I is a manual of principles and suggestions concerning a course of study. Part II contains the detailed outline of the course organized by grades. The work of each grade is arranged in accordance with the following general scheme: (I) aims of instruction, very specifically stated and discussed in such a way as to aid the teacher in carrying them out; (2) suggestive topics in the illustrative

${ }^{1}$ Standards in English. By John J. Mahoney. Yonkers-on-the-Hudson, N.Y.: World Book Co., 1917. Pp. xi+198. Paper, \$o.9o. 
material; (3) illustrative oral efforts; (4) common errors of speech, misspellings, etc.; (5) hints and helps concerning what to do and how to do it; (6) preparation for routine work. One of the outstanding characteristics of the course is the setting forth of definite standards of achievement of which the children have been proven to be capable of attainment. The style of the book is direct and non-technical and it should be put in the hands of elementary-school teachers for the distinct improvement of oral and written work in English.

3. The use of practice exercises in arithmetic.-The design and use of standardized tests can be made effective in school practice only with the consequent construction and use in the classroom of corrective practice material, the aim of which is to remedy the defects revedled by the tests. In the last three years several different sets of practice exercises in the four fundamentals in arithmetic have been devised. Many school systems have made use of them. Aside from the commercial aspect of the matter, school teachers are distinctly interested in any experimental determination of the relative results obtained with the use of these exercises. It is with a great deal of interest, therefore, that we report Professor Mead's Experiment in the Fundamentals. ${ }^{\text {. }}$ This is a systematic attempt to determine experimentally the value of the Courtis Standard Practice Tests and Thompson's Minimum Essentials. Nine hundred fifth-grade children, from fourteen Cincinnati schools, divided into two groups of approximately twenty-four in a class, were trained fifteen minutes daily, February to May, inclusive, I916, with the two types of material. Preliminary and final standard tests were given to each group, using the Courtis Tests, Series B. The work of the four months was done by the controlled method with respective material for each group. Median accomplishments were used as methods of comparison of the two groups. Scores for the pupils were obtained both in the preliminary and final tests, and from the daily scores made by practice exercises. These were checked up by the opinions and criticisms of teachers and principals. The statistical results show, in the main, the superiority of the Courtis material. It is to be hoped that such purely objective comparisons will be made of the scientific and practical material which is coming out as a result of the quantitative movement in education.

4. A technical study of school boards.-One of the most critical administrative problems which is now being studied by the quantitative method is that of the relations between boards of education and their professional chief executives. Last year the Department of Superintendence, working through a committee of school men, made a study of this problem by the question-blank method. Their findings, which show the real need for reform in the present

I Experiment in the Fundamentals. By Cyrus D. Mead. Yonkers-on-the-Hudson, N.Y.: World Book Co., r9r7. Pp. xiv+54. \$o.6o. 
differentiation of school control between lay and professional agents, have been published. During the last three years several careful analyses have been made of this problem in our larger city systems by survey staffs. The most noted of these is that reported by Ayres in his School Organization and Administration in the Cleveland Survey Report. With this attempt to determine the present status of such problems by careful personal investigation there has been needed a tabular survey of the published records of school systems throughout the country. Dr. Theisen's Monograph on the City Superintendent and the Board of Education ${ }^{\mathrm{I}}$ comes to satisfy this need.

This reports the analysis of rules and regulations and board minutes in I60 cities, varying in size from Westport, Mass., with a population of 3,000, to New York City. It includes nearly all of the larger cities. The study is concerned with the way in which provision is made in the by-laws of boards for the performance of duties which commonly devolve upon them. It is concerned also with what boards do, whether it be the result of inactivity or overactivity, or whether it be the result of legal restriction or a combination of these factors.

Even a casual examination of state school laws is sufficient to convince the student of educational administration that the statutes do not prevent boards from knowing what they are doing; from bending every effort (except in San Francisco, which provides for popular election of the superintendent) to secure as their chief executive officer the most capable man available; from looking to their chief executive for recommendations on questions of policy; from requiring of their executive officers adequate reports of the educational progress and business conditions of the school system; from an intelligent discussion of such reports; from requiring their chief executive and his assistants to submit a detailed analysis of proposed expenditures and probable receipts, showing just what each unit of educational endeavor will probably cost; from centering their own attention on large questions rather than too trivial matters. An examination of school laws reveals further that boards are not deterred by legal provisions from refusing to appoint teachers and other officers, so far as the appointive power rests with the board, except as they are nominated and recommended by the chief executive. It does not prevent them from refusing to squander their own time in listening to personal complaints and communications unless it is found that the matter in question cannot be adjusted satisfactorily by those whom it employs to administer its system of education.

The investigation studies: the size of board, number of members, number and size of committees, a description of the powers and of the actual performance of these committees, the conception which the board has formed of the professional aspects of the superintendent's position, how the board spends its time, the way in which it centralizes or differentiates matters of school control, the degree to which the board is equipped to pass upon the recommendations

${ }^{2}$ City Superintendent and the Board of Education. By W. W. Theisen, Teachers College, Columbia University, Contributions to Education, No. 84, 1917. Pp. ix + 337 . 
of the superintendent, etc. The need for a reform in administrative organization is pointed out with careful discussions showing what is done in the business world.

This study puts in printed form a very much needed compilation of the present legalized relations between boards of education and superintendents. If made use of by school officers it will lend impetus to the movement which is aimed at making clear the best differentiation of power between lay and professional officers.

TWO NEW BOOKS ON SCHOOL HEALTH WORK

5. In The School Nurse Dr. Struthers has written down the outcome of more than fifteen years of successful work as nurse, organizer, and administrative head of the departments of school nursing in New York City, Toronto, Canada, and several other cities. ${ }^{x}$ The book is a survey of the duties and responsibilities of the nurse in the maintenance of health and physical perfection and the prevention of disease among school children. In introducing the problem the author shows that the fundamental influence of the school nurse has been felt in changing a health policy which excluded diseased children from school and next set out upon a campaign of cure for school children to the present function of preventing disease and its spread by intimate contact with the home. In other words, the school nurse is becoming a most important professional intermediary between the home and the school. $\checkmark$ This book is both a book of general principles and a manual of specific directions to those engaged in the work. It contains, for example, a brief historical discussion (chap. ii) showing the recency of medical inspection of schools and describing briefly the origin and growth of the movement in a dozen of the larger cities of the country. In chapter iii problems of organization of school-nurse work in a city are discussed with the inclusion of both general principles and very detailed suggestions for the inauguration of the department. In this regard the book becomes a valuable "case" handbook. Specific directions are given concerning how to begin the daily routine of the nurse and assistants, her duties in class inspection, special examinations, and home visiting. The author carries out the handbook idea in chapter iv by publishing many pages of specific rules and regulations for the guidance of medical and dental inspectors and nurses. The issue that has arisen over the administration of medical and dental inspection of schools-whether it shall be by the board of health or by the board of education-is debated in chapter $\mathrm{v}$, the position being taken that the board of education is the proper agency for school health control. Specific suggestions are made for state regulations of such auxiliary school work which should be of great value to legislative committees and those interested in propagating the movement. Specific directions for the formation of little mothers'

${ }^{\prime}$ The School Nurse. By Lina Rogers Struthers, R.N. New York: G. P. Putnam's Sons, 1917. Pp. xiv+294. \$1.75. 
classes and school baby clinics are presented in chapter vii, and open-air schools in chapter viii. The discussion of specific diseases in chapter ix contains a detailed manual of suggestions for diagnosis and treatment as far as these are proper functions of the school nurse. Tuberculosis and the organization of anti-tuberculosis work in the public schools, derangements of nutrition, large tonsils and adenoids, defective hearing and vision, dental caries and school dental clinics, are presented with an emphasis upon a practical application of principles which will be helpful to the nurse. The book closes with a discussion of the qualifications, habits, and ideals of the school nurse. The appendix contains a complete system of reports and records for a department of medical inspection in a city school system.

6. The remarkable changes in social and economic life which have been typified by the disappearance of child work, the increased congestion in cities, the rapid overburdening of the nervous system, and the constant lowering of the physical vitality of the race have resulted in a definite demand for the organized treatment of the physical upbuilding of men in their leisure time.

If the tendencies which were ushered in with the coming of the public school, the age of machines, and the concentration of people in great cities were to go on for a generation or two more, it would mean the elimination of the race. It is absolutely essential that we should surround our children by more wholesome conditions, that we should give to them a more stable nervous system and a more robust physique than the average school child of today possesses.

Dr. Curtis' recent book ${ }^{\mathrm{r}}$ from which the foregoing quotation is taken is an attempt to give superintendents of schools, social workers, mothers' clubs, and playground commissions that information on the play movement which will be most helpful to them.

The word "play" has been used in its broadest sense as the effort has been to give a general picture of those movements which mean a better utilization of leisure time and an increase in the joy of life. Its main emphasis has been upon the play of children, but it deals also to a less degree with recreation for adults. It aims to show the place of school playgrounds, of the municipal playground, the park, and various commercial forms of recreation in a general scheme for a city.

As was the case of nearly every extra-traditional curricular activity that has eventually tied up with the public schools, the play movement in the United States started through private endeavor and financial support. The author gives a brief sketch of this movement and points out the fivefold aspect of this development. He says there are five play movements: first, the movement to provide a place for play where children can go in their leisure time; second, the attempt to put organized play into the program of the public schools; third, the movement to furnish an adequate opportunity for an outdoor life

I The Play Movement and Its Significance. By H. S. Curtis. New York: Macmillan, I917. Pp. xv+346. \$1.50. 
and play for children below the school age; fourth, the movement for public recreation; and fifth, the distinct movement for the development of the spirit of play. The author builds upon his previous book, Education through Play, and gives first an abbreviated discussion of the essential principles which were developed there. He has based his discussion and criticism of the attempts of the school in this direction on three desiderata: (I) adequate playgrounds, (2) adequate time for play, (3) adequate supervision. He particularizes the general discussion by a detailed presentation of the Gary system in which play has been so successfully organized.

The book is not merely a general sketch of the movement, and while it is not proper to characterize it as a manual of instruction for those who are organizing play work it does illustrate each aspect of the work by detailed discussions of the carrying on of organized recreational facilities in many cities. The book is characterized by an intelligent recognition of the needs of city people for play and is filled from cover to cover with definite concrete suggestions concerning what to do and how to do it. Not the least practical of its chapters is the one which gives a very good discussion of the organization of play activities in institutions for the blind, the deaf, the feeble-minded and the insane, industrial schools, reformatories, penitentiaries, sanitariums and hospitals.

7. A textbook in educational psychology. may be classified according as their emphasis is upon the psychological or the educational phase of the subject. One may start with the facts and principles of general psychology and select those which seem to be of most significance for education, and then make whatever application can be found of these facts. When educational psychology is of this type the topics and their arrangement usually suggest, primarily, the psychological starting-point. The other method is to start from the education problems, to put them in psychological terms, and then attempt their solution.

Dr. Gordon's text ${ }^{2}$ is of the first type. Furthermore, it is a rather extreme example of this type, in that many of the facts and principles which are selected for treatment seem to have only remote application to educational problems. In fact, the book does not differ very greatly from a general text in psychology. This constitutes in the mind of the reviewer a basis of criticism, since the more fruitful kind of educational psychology is coming to be regarded as that which deals more directly with the practical problems.

The nature of the book may be seen from a brief survey of its contents. After an introductory chapter, five chapters are devoted to various aspects of the child's development; one is given to physical growth, two to instinct, one to motor development, and one to the development of the sensations. One

I This review is contributed by Professor F. N. Freeman, University of Chicago.

${ }^{2}$ Educational Psychology. By Kate Gordon. New York: Henry Holt \& Co., I917. Pp. 294. 
chapter is then given to the learning process, which is concerned chiefly with the simpler development of manual skill. One is given to imagination, in which the chief emphasis is upon such matters as tests of imagery and the theories of the imagination. There is a chapter on observation and report which has more obvious application to the work of the school, and one on memory, which takes up some of the factors and problems of memorizing. These factors, such as recency, frequency, vividness, etc., might be presented so as to bring out somewhat more clearly the practical rules which are to be derived from them. Three chapters are given to reasoning, one of them of seventeen pages being devoted to syllogism. In contrast to this somewhat extended treatment for such a text of a subject which has relatively little practical bearing even upon the ordinary process of thinking, but eight pages are devoted to the subject of transfer of training, which touches upon a real and important issue in education. After a chapter of fourteen pages on attention, feeling, and will, three chapters are devoted to the psychology of the teaching of language, drawing, and arithmetic.

This text is designed for use in normal schools and colleges, and presupposes an introductory course in psychology. Since a previous course in psychology is assumed, there are certain parts of the discussion of the nature of description and definition which do not seem to be necessary. On the other hand, the general mode of treatment makes the book suited to an advanced type of student and too difficult at least for normal-school students. The style is a rather disconnected one, and the treatment rather uneven, due to the fact that the discussion is based largely upon direct citation of original sources. One hundred and fifty-two such citations are made in the book. While this method is desirable for advanced students and may be thought desirable from the point of view of scientific accuracy, it is confusing to the relatively immature student. It is this preoccupation with the experimental sources, perhaps, which causes some relatively minor topics to be treated.with greater fulness than other practically more important ones. For example, six pages are devoted to a discussion of left-handedness, which is more than is given to play. There is no discussion at all of the changes in play with age. In the discussion of motor development, there is no account of the growth in precision or rapidity of movement. In the discussion of instinct, seven pages are devoted to sleep and dreams and none to the social instincts or attitudes.

While the book does present a rather useful collection of experimental facts with reference to certain phases of psychology as related to education, it is defective as a text in educational psychology because of its too great emphasis upon the psychological aspect of the subject, because of its style, which is unsuited to relatively immature students, and because of its uneven emphasis upon different topics. 


\section{BRIEF DESCRIPTIVE STATEMENTS OF NEW PUBLICATIONS}

The School Assembly. By A. Nifenecker. New York: Department of Education, Division of Reference and Research. Publication No. I5, 1917. Paper. Pp. I07.

A handbook of auditorium exercises, put in the hands of principals responsible for conducting school assemblies; a manual of illustrative material. Shows the true aims and values of assemblies and gives much detailed concrete material to be used in organizing programs; for example, stereopticon slides, institutions that loan them, and collections of material which are available. Motion picture films, methods of using. Lectures by teachers, pupils, outsiders. Music, choral, instrumental, appreciation, phonographs, recitals. Bible readings, declamations and recitations, storytelling, selection of material, method. Dramatizations, plays, festivals, folk dances, mimetic drills, debates, contests. Forums, question boxes.

The Profession of Teaching. By O. I. and M. V. Woodley. Boston: Houghton Mifflin Co., I9I7. Pp. ix+325. \$I.35.

A book for teachers and others interested in the profession of teaching, nontechnical and addressed to the average or general reader. The first chapter discusses professions in general and attempts to establish the position of teaching as a profession. Remaining chapters deal with the demands made upon teachers by the larger idea of education and aim at giving teachers an understanding of the means to be employed in meeting those demands. Important topics discussed are: school ethics, aims, social function of school, learning process, teaching process, recitation, subject-matter, vocational education and guidance. Well-chosen lists of selected readings are given after each chapter and also exercises for reflective thinking. Has a good index.

Lancasterian System of Instruction in Schools of New York. Teachers College Contributions to Education, No. 8I. Reigart, I9I7. Cloth. 8vo, pp. v+ ro5.

An intensive study in the history of education treating of part played by the monitorial plan in the development of New York City's public-school system from I 805 to r 853 . Describes origin and rise of Lancaster's plan and gives reason for introduction into New York. Deals quite specifically with school organization and classification of pupils and gives specimens of floor plans, curricula, and programs. Methods of teaching reading, arithmetic, science, manual training, and religious and moral education are indicated. School inspection, teacher-training, and the good and evil effects of the system are discussed. Good bibliography. Analytical table of contents.

Apprenticeship and Apprenticeship Education. Colonial New England and New York. Teachers College Contributions to Education, No. 85. Seybolt, I9I7. Cloth. 8vo, pp. I2I.

Historical dissertation dealing with early trade education. The rise of the apprenticeship system in England and its transplanting to the American Colonies are thoroughly described. Educational aspects of the practice of apprenticeship in New Plymouth and Massachusetts Bay colonies, Connecticut, New Haven, and Rhode 
Island colonies, and in New York Province are indicated. Based upon legislation, court orders, indentures, wills, and other original sources. Good conclusion. Appendix contains a few transcripts of original documents. Extensive bibliography of source material.

Statistical Methods Applied to Education. By H. O. RugG. Boston: Houghton Mifflin Co. Pp. xiv +426. \$2.00. [To be reviewed in next issue.]

A complete textbook for students of education, superintendents, and teachers untrained in mathematics, of the methods of treating numerical data collected on school problems. A carefully graded discussion showing the lay reader the use of statistical methods in education, the collection and tabulation of data, the derivation, computation, and interpretation of each of the methods now used in the study of school problems: the frequency distribution, averages, measures of variability, ideal curves and their use, measures of relationship, the use of statistical methods in reporting school facts.

Illustrative Problems in Educational Statistics. By H. O. RugG. 35 problems.

Published and distributed by the author, School of Education, University of Chicago. Paper. \$o.6o.

A book of statistical problems designed to accompany the author's textbook. For administrative officers and teachers as well as formal class use in normal schools and schools of education. Provides opportunity for practice in working problems which involve each of the statistical methods now used by school men.

News Writing. The gathering, handling, and writing of news stories. By M. Lyle Spencer. D. C. Heath \& Co., I9i7. Pp. $35^{2}$.

Contents: Organization of the paper, the different editors and their duties, the mechanical department, speed devices, the business department. The news story: what is news, interest, sources, methods of getting stories, interviewing, etc. Types of stories: as interviews, speeches, courts, accidents, etc.

\section{CURRENT EDUCATIONAL PUBLICATIONS RECEIVED IN SEPTEMBER AND OCTOBER}

(Detailed discussions of some of the following publications will appear later.)

\section{A. GENERAL EDUCATIONAL THEORY AND PRACTICE}

De Hovre, Fr. German and English Education. A Comparative Study. New York: Scribner, I9I7. Pp. I08.

DIFFENDORFER, RALPH E. Missionary Education in Home and School. New York: Abingdon Press, I9I7. Pp. 407. \$1.50.

Reed, ANna Y. Newsboy Service. A Study in Educational and Vocational Guidance. Yonkers-on-Hudson: World Book Co., I9I7. Paper. Pp. xxviii+r 75 . \$o.60.

Surth, Henry Lester. A Survey of a Public-School System. New York: Teachers College, Columbia University, r91 7. Pp. xii+304.

(To be reviewed in next issue.) 
Snedden, David. Educational Sociology. A Digest and Syllabus. Part I: Introduction. New York: Teachers College, Columbia University, I9I7. Paper. Pp. 37. \$0.55.

- Educational Sociology. A Digest and Syllabus. Part II: Applications to Curricula and Studies. New York: Teachers College, Columbia University, I917. Paper. Pp. 70. \$0.80.

Teachers of the Horace Mann Elementary School. The Curriculum of the Horace Mann Elementary School. New York: Teachers College, Columbia University, I9I7. Paper. Pp. iv+ 138.

Winchester, Benjamin S. Religious Education and Democracy. New York: Abingdon Press, 1917. Pp. 293.

\section{B. TEXTBOOKS FOR THE ELEMENTARY GRADES}

Burroughs, John. The Wit of a Duck. Boston: Houghton Mifflin Co., I9I3. Pp. 96. \$0.28.

Chaplin, Alethea. A Treasury of Fairy Tales. New York: Thomas Y. Crowell Co. I2mo, pp. I29. \$0.50. Illustrated.

Contents: "Babes in the Wood," "Puss in Boots," "Red Riding Hood," and other stories.

Cory, David. The Adventures of Puss in Boots, Jr. New York: Harper, I9I7. Pp. 149. \$0.50.

Gask, Lilian. A Treasury of Folk Tales. New York: Thomas Y. Crowell Co. Illustrated. I $2 \mathrm{mo}, \mathrm{pp}$. I 23 . \$O.50. others.

Contents: "The Golden Fish" (Russian), "The Two Brothers" (Slovak), and

Gregg, F. M. Hygiene as Nature Study. Published by author, Peru, Neb. Paper. Illustrated. Pp. I69. \$o.70.

A noteworthy attempt to vitalize the teaching of physiology and hygiene.

Harris, Ada Van Stone, and Waldo, Lillian McLean. Number Games for Primary Grades. Chicago: Beckley-Cardy Co. Pp. I23. \$o.60.

Irving, Washington. Tales from the Alhambra (adapted by Josephine V.

Brower). Boston: Houghton Mifflin Co., I917. Pp. 192. \$0.44.

Kipling Stories and Poems Every Child Should Know. Book I. Edited by Mary E. Burt and W. T. Chapin. Boston: Houghton Mifflin Co. Pp. vi+I42. \$o. 44 .

Miller, Albert H. The Modern Speller. Chicago: M. A. Donohue \& Co., I9I 7. Pp. 88.

To teach correct spelling of the words most frequently used, with emphasis on permanent retention.

Meyer, Zoe. The Outdoor Book. For second school year. Boston: Little, Brown \& Co., I9I7. Illustrated. Pp: vii+123. \$o.40. 